\title{
Clinical Study \\ Objectively Measured Physical Activity and Body Mass Index in Preschool Children
}

\author{
Susana Maria Coelho Guimarães Vale, ${ }^{1}$ Rute Marina Roberto Santos, ${ }^{1}$ \\ Luísa Maria da Cruz Soares-Miranda, ${ }^{1}$ Carla Marisa Maia Moreira, ${ }^{1}$ Jonatan R. Ruiz, ${ }^{2}$ \\ and Jorge Augusto Silva Mota ${ }^{1}$ \\ ${ }^{1}$ Research Centre in Physical Activity, Health and Leisure, Faculty of Sport, Porto University, 4200-450 Porto, Portugal
${ }^{2}$ Department of Biosciences and Nutrition, Unit for Preventive Nutrition, Karolinska Institute, 14183 Stockholm, Sweden \\ Correspondence should be addressed to Jorge Augusto Silva Mota,jmota@fade.up.pt
}

Received 28 January 2010; Revised 3 June 2010; Accepted 16 June 2010

Academic Editor: Lars B. Andersen

Copyright ( 2010 Susana Maria Coelho Guimarães Vale et al. This is an open access article distributed under the Creative Commons Attribution License, which permits unrestricted use, distribution, and reproduction in any medium, provided the original work is properly cited.

\begin{abstract}
Aim. To examine the association between objectively measured physical activity (PA) and body mass index (BMI) in preschool children. Methods. The study comprised 281 children (55.9\% boys) aged from 4 to 6 years. PA was measured by accelerometer. Children were categorized as non-overweight (NOW) and overweight/obese (OW) according to the sex-adjusted BMI $z$-score $(<1$ and $\geq 1$, resp.). Results. Total and moderate intensity PA were not associated with BMI. We observed that a higher proportion of OW children were classified as low-vigorous PA compared to their NOW peers (43.9 versus $32.1 \%$, resp., $P>.05)$. Logistic regression analysis showed that children with low-vigorous PA had higher odds ratio (OR) to be classified as OW compared to those with high-vigorous PA $(\mathrm{OR}=4.4 ; 95 \% \mathrm{CI}$ : 1.4-13.4; $P=.008)$ after adjusting for BMI at first and second years of life and other potential confounders. Conclusion. The data suggests that vigorous PA may play a key role in the obesity development already at pre-school age.
\end{abstract}

\section{Introduction}

The prevalence of childhood obesity has been rising during the past decades in many parts of the world [1]. In Portugal, there is a high prevalence of overweight and obese children [2] and adolescents [3]. This picture is particularly alarming owing to the increasing risk of developing cardiovascular diseases in overweight and obese individuals $[4,5]$. Over the long term, childhood/adolescence overweight is strongly associated with adult obesity $[6,7]$. Therefore, it is of clinical and public health importance to examine the risk trends in order to develop effective preventive strategies targeting those at risk start as early as possible.

Human obesity is a multifactorial disorder where both genes [8] and lifestyle factors, including diet and physical activity [9] are important contributors. Both maternal and paternal body mass index (BMI) has also a strong influence on offspring's risk of obesity $[10,11]$. Other determinants of childhood obesity include birth weight and weight gain that occur during the first years of life [12-14].

It has been suggested that obesity during the pre-school years is associated with other clinical factors easily assessed at birth [15]. For instance, it was found an association between birth weight and the risk of being obese in children at the age of $4,8,10$, and 12 years [16].

Besides the previously mentioned factors, there exist other potentially modifiable factors that increase the risk of overweight in childhood and adolescence. These include: (i) intrauterine life: excessive gestational weight gain [17, 18], and maternal smoking during pregnancy $[13,19,20]$; (ii) infancy and pre-school period: reduced breastfeeding duration [21], excessive weight gain in the first 2 years of life [12, 22], excessive television [23-25], short sleep duration $[12,26,27]$, and low levels of physical activity (PA) [28-30].

Studies examining the associations between PA and body fat in young children are scarce $[12,28,30]$, and to the best of 
our knowledge, few studies have estimated the associations between objectively measured PA and BMI in preschoolers $[28,30]$. Furthermore, there is no information available in Portuguese population.

The purpose of this study was to analyze the association between objectively measured PA and BMI in Portuguese preschoolers.

\section{Methods}

2.1. Participants and Data Collection. This is a cross-sectional study carried out in Portuguese (metropolitan area of Porto) kindergartens enrolled in the Preschool Physical Activity, Body Composition and Lifestyle Study (PRESTYLE). A total of 281 healthy pre-school children (55.9\% boys) aged 46 years with complete information on the variables of interest were included in the study. Data collection took place between April 2009 and November 2009.

Informed written consent was obtained from parents and school supervisors. Study procedures were approved by the Portuguese Foundation for Science and Technology and by the Scientific Board of Physical Activity and Health PhD program.

2.2. Anthropometric Measures. Body weight and height were measured by standard anthropometric methods. Body weight was measured to the nearest $0.10 \mathrm{~kg}$, with participants lightly dressed (underwear and tee-shirt) using a portable digital beam scale (Tanita Inner Scan BC 532). Body height was measured to the nearest millimetre in bare or stocking feet with children standing upright against a Holtain portable stadiometer (Tanita). The measurements were repeated twice and the average was recorded. BMI was calculated as body mass (kg) divided by height $(\mathrm{m})$ squared. Children were classified as either non-overweight (NOW) or overweight (OW) according to the sex-adjusted BMI z-score ( $<1 \mathrm{SD}$ and $\geq 1$ SD, respectively). Children were evaluated during school day by trained teachers.

2.3. Physical Activity. PA was measured using Actigraph accelerometers, model GTM1 (Pensacola, FL 32502. USA). This is a small, lightweight, uniaxial device. This accelerometer produces "raw" output in activity counts per minute (cpm), which gives information about the total amount of PA [31]. The accelerometer output can also be interpreted using specific cut points, which describes different PA intensities PA. Data reduction, cleaning, and analyses of accelerometer data were performed as described elsewhere [32, 33]. Data were analysed using specific paediatric cut points, which have been validated for young children: $\geq 1100$ and $\leq 1680 \mathrm{cpm}$ for low PA [34], >1680 cpm for moderate PA, and $>3360 \mathrm{cpm}$ for vigorous PA (VPA) [35]. In this study, the epoch duration was set to 5 seconds, which seems to be more accurate and suitable concerning the spontaneous and intermittent activities of the young children [36].

A minimum of 10 hours per day was considered as valid data for the analysis. Parents were instructed to place the accelerometer on the child right after waking up and remove it before going to sleep. The accelerometer was adjusted at the child's right hip by an elastic waist belt under clothing (own cloth and school coat). A data sheet was given to the children's teachers, who were instructed to record the time when the child arrived and left the school. Activities were not prescribed or directed by the teachers or researchers. All children participated in normal activities with their classmates.

All PA intensity levels were defined by sex- and agespecific tertiles. Children belonging to the first, second, and third tertiles were defined as low, middle and high PA levels, respectively.

\subsection{Potential Confounders}

2.4.1. Pre- and Postnatal and Lifestyle Factors. Mothers reported information regarding gestational weight gain, maternal smoking during pregnancy, birth weight as well as body weight and height during their offspring's first and second year of life. Gestational weight gain was categorized according to Institute of Medicine [37] as below, optimal, and above gestational weight gain, while maternal smoking during pregnancy was categorized as YES or NO.

Mothers also reported the amount of screen time (watching television and/or playing videogames) the child spends daily as well as the sleeping time for both week days and weekends. Screen time questions were analyzed as continuous variables (converted to minutes) and also evaluated as a dichotomous variable based on young children recommendation [38]. Then, children were classified as those who accomplished guidelines (watching $<2$ hours/day) and those who did not (watching $\geq 2$ hours/day).

2.4.2. Mother Information. Mothers reported their body weight and height, and we calculated BMI. Mothers were categorized as normal weight $\left(18.5 \mathrm{~kg} / \mathrm{m}^{2} \geq \mathrm{BMI}<25 \mathrm{~kg} / \mathrm{m}^{2}\right)$; overweight $\left(25 \mathrm{~kg} / \mathrm{m}^{2} \geq \mathrm{BMI}<30 \mathrm{~kg} / \mathrm{m}^{2}\right)$, and obese (BMI $\geq 30 \mathrm{~kg} / \mathrm{m}^{2}$ ) [39].

Socioeconomic status (SES) was defined as the mother's educational level and occupation [40]. The SES was defined based upon Portuguese Educational system a 9 years' education or less subsecondary level (scored as 1), 10-12 years' education, secondary level (scored as 2) and higher education (scored as 3). Levels 1, 2, and 3 were considered as low, middle, and high SES [41].

2.5. Statistical Analysis. Means and standard deviations were calculated to describe children's characteristics by weight status (i.e., NOW and OW).

Comparisons between weight status and PA patterns were conducted with $t$-test for continuous variables and chisquare test for categorical variables.

Following bivariates correlation analysis we conducted logistic regression to examine the association between weight status and all other variables (physical activity patterns, gestational weight gain, smoking during pregnancy, BMI first year of life, BMI second year of life, daily screen time, daily sleep time). 
TABLE 1: Descriptive statistics of study participants.

\begin{tabular}{|c|c|c|c|c|}
\hline & $\begin{array}{c}\text { All Group } \\
N=281\end{array}$ & $\begin{array}{c}\mathrm{N}-\mathrm{OW} \\
N=240\end{array}$ & $\begin{array}{c}\text { OW } \\
N=41\end{array}$ & $P$ \\
\hline Age (years) & $5.03 \pm 0.81$ & $5.01 \pm 0.82$ & $5.14 \pm 0.72$ & .264 \\
\hline Weight (Kg) & $21.11 \pm 4.42$ & $20.12 \pm 3.14$ & $27.92 \pm 5.73$ & $<.001$ \\
\hline Height (m) & $1.11 \pm 0.08$ & $1.10 \pm 0.08$ & $1.14 \pm 0.08$ & .005 \\
\hline $\mathrm{BMI}\left(\mathrm{Kg} / \mathrm{m}^{2}\right)$ & $17.03 \pm 2.12$ & $16.43 \pm 1.29$ & $21.11 \pm 2.20$ & $<.001$ \\
\hline BMI z-score & & $-0.28 \pm 0.61$ & $1.92 \pm 1.04$ & $<.001$ \\
\hline TPA (minutes) & $134 \pm 35$ & $134 \pm 36$ & $133 \pm 29$ & .863 \\
\hline MPA (minutes) & $58 \pm 14$ & $58 \pm 14$ & $58 \pm 13$ & .882 \\
\hline VPA (minutes) & $38 \pm 14$ & $38 \pm 14$ & $35 \pm 12$ & .293 \\
\hline \multicolumn{5}{|c|}{ Physical Activity Patterns (\%) } \\
\hline \multicolumn{5}{|l|}{ TPA } \\
\hline Low Activity & 32.4 & 33.3 & 26.8 & \\
\hline Middle Activity & 34.9 & 32.9 & 46.3 & .249 \\
\hline High Activity & 32.7 & 33.8 & 26.8 & \\
\hline \multicolumn{5}{|l|}{ MPA } \\
\hline Low MPA & 32.4 & 33.3 & 26.8 & \\
\hline Middle MPA & 35.2 & 33.3 & 46.3 & .273 \\
\hline High MPA & 32.4 & 33.3 & 26.8 & \\
\hline \multicolumn{5}{|l|}{ VPA } \\
\hline Low VIG & 33.8 & 32.1 & 43.9 & \\
\hline Middle VIG & 33.5 & 32.5 & 39.0 & .064 \\
\hline High VIG & 32.7 & 35.4 & 17.1 & \\
\hline
\end{tabular}

TPA: Total Physical Activity; MPA: Moderate Physical Activity; VPA: Vigorous Physical Activity.

A stepwise logistic regression analysis was performed to examine the association between PA and weight status, adjusted for all variables independently associated with weight status.

Statistical analysis was performed using the SPSS 17.0 software (SPSS Inc., Chicago, IL, USA). The level of significance was set at $P \leq .05$.

\section{Results}

Table 1 shows descriptive statistics of preschoolers and parents by overweight status. The prevalence of overweight was $14.6 \%$. Overweight (OW) children were heavier, taller, and had higher BMI than their NOW counterparts $(P \leq .05)$. We observed no statistical significant differences between weight status categories in minutes of total, MPA and VPA. However, the data showed that a proportion of OW children $(43.9 \%)$ were classified low VPA compared to NOW children (32.1\%) $(P>.05)$.

Logistic regression analysis showed that children with low vigorous PA had higher odds ratio $(\mathrm{OR})$ to be classified as $\mathrm{OW}$ compared to those with high vigorous $\mathrm{PA}(\mathrm{OR}=4.4$; 95\% CI: $1.4-13.4 ; P=.008$ ) after adjusting for BMI at first and second years of life and other potential confounders (Table 2).

\section{Discussion}

This study examined the association of different PA intensity levels with weight status of Portuguese preschoolers after adjusting for several potential confounding factors. This is an important and relevant topic since, to the best of our knowledge, little is known about how PA intensity is associated with obesity in pre-school children. Our data showed that differences in levels of VPA were associated with weight status in children as young as 4 to 6 years. This is worthy to notice because our data suggest that the VPA influenced the change in BMI from those earlier ages. Despite that, no statistical significant differences were found for levels of total and moderate PA.

Our findings concur with other studies showing that low levels of VPA were associated with body fatness during the adiposity rebound period [30]. Further, they also agree with studies in children and adolescents showing that only VPA (but not lower intensity levels) was associated with body fat [42]. Additionally, it was shown that within intervention groups, those who participated regularly and maintained the highest heart rates during PA sessions showed the greatest decreases in body fat and the greatest increases in bone density $[43,44]$. On the other hand, adolescents who engaged in relatively large amounts of free-living vigorous PA were likely to be relatively fit and lean. [45]. These findings are worth commenting in terms of both PA interventions and public health policies.

The large standard deviations found in our study suggest a wide individual variations and highlight the importance of the participants' intraindividual variability in PA behaviour. Therefore, variation in PA levels may be particularly important in preschool children with regard to weight status. While there is a need to better understand the factors that 
TABLE 2: Univariable and multivariable logistic regressions.

\begin{tabular}{|c|c|c|c|c|}
\hline & $\begin{array}{c}\text { Univariable } \\
\text { Effects (odds } \\
\text { ratio }(95 \% \mathrm{CI}))\end{array}$ & $P$ value & $\begin{array}{c}\text { Multivariable } \\
\text { Stepwise } \\
\text { effects* (odds } \\
\text { ratio }(95 \% \mathrm{CI}) \text { ) }\end{array}$ & $P$ value \\
\hline TPA (Low TERTILE) & $1.7(0.8-3.9)$ & $>.05$ & & \\
\hline TPA (Middle TERTILE) & $1.0(0.4-2.5)$ & $>.05$ & & \\
\hline \multicolumn{5}{|l|}{ TPA (High TERTIL)—REF } \\
\hline MPA (Low TERTILE) & $1.7(0.8-3.9)$ & $>.05$ & & \\
\hline MPA (Middle TERTILE) & $1.0(0.4-2.4)$ & $>.05$ & & \\
\hline \multicolumn{5}{|c|}{ MPA (High TERTIL)—REF } \\
\hline VPA (Low TERTILE) & $2.8(1.1-7.2)$ & .027 & $4.4(1.4-13.4)$ & .008 \\
\hline VPA (Middle TERTILE) & $2.5(0.9-6.4)$ & $>.05$ & $2.9(0.9-8.8)$ & $>.05$ \\
\hline
\end{tabular}

TPA: Total Physical Activity; MPA: Moderate Physical Activity; VPA: Vigorous Physical Activity

* Adjusted for Birthweight. BMI 1 year. BMI 2 years. Gestacional Weight Gain. Maternal Smoking during pregnancy. Scream and Sleep Time and Mother BMI and Education.

influence PA in preschoolers and to learn how to help them to become more active, our study shows that PA promotion and interventions should focus on the more intense PA activities. Children have a natural tendency towards movement, there is information suggesting a decline of discretionary time on children's daily life [29] and, thus, the time allocated to spontaneous PA, which, in turn, tend to be highly active [46] it is reduced and several sedentary behaviors such as TV viewing, video games, and other activities involving many hours standing took the lead on children's daily behaviour $[12,24]$. Therefore, promotion of organized PA programmes such as physical education at schools and organized sports activities [29] that usually request more intense activities must be taken into account when PA promotion strategies are being developed.

Some limitations of this study should be recognized. First, the study included pre-school children from one metropolitan area, which made it difficult to generalize these findings. Secondly, it is not possible to inferr causal relationships between pre-school PA level and overweight status with such a cross-sectional study design. Nevertheless, this study focuses on the assessment of PA levels in a preschool sample using an objective measure, which enhances the confidence of our findings owing to the fact that accelerometers provide more valid PA assessment in children [35].

\section{Conclusion}

Our data suggests that VPA may play a key role in the obesity development already at pre-school age.

\section{Acknowledgment}

This paper was supported in part by Grant from Portuguese Foundation for Science and TechnologySFRH/BD/30059/2006.

\section{References}

[1] D.-S. Akram, A. V. Astrup, T. Atinmo et al., "Obesity: preventing and managing the global epidemic," Technical Report Series 894, World Health Organization, Geneva, Switzerland, 2000.

[2] C. Padez, T. Fernandes, I. Mourão, P. Moreira, and V. Rosado, "Prevalence of overweight and obesity in 7-9- yearold Portuguese children: trends in body mass index from 1970-2002," American Journal of Human Biology, vol. 16, no. 6, pp. 670-678, 2004.

[3] J. Ribeiro, S. Guerra, A. Pinto, J. Duarte, and J. Mota, "Prevalencia de excesso de peso e de obesidade numa populaçao escolar da area do grande Porto, de acordo com diferentes pontos de corte do indice de massa corporal," Acta Pediatrica Portuguesa, vol. 34, no. 1, pp. 21-24, 2003.

[4] D. S. Freedman, L. K. Khan, W. H. Dietz, S. R. Srinivasan, and G. S. Berenson, "Relationship of childhood obesity to coronary heart disease risk factors in adulthood: the Bogalusa Heart Study," Pediatrics, vol. 108, no. 3, pp. 712-718, 2001.

[5] J. Miller, A. Rosenbloom, and J. Silverstein, "Childhood obesity," Journal of Clinical Endocrinology and Metabolism, vol. 89, no. 9, pp. 4211-4218, 2004.

[6] W. H. Dietz, "Overweight in childhood and adolescence," New England Journal of Medicine, vol. 350, no. 9, pp. 855-857, 2004.

[7] S. S. Guo, W. Wu, W. C. Chumlea, and A. F. Roche, "Predicting overweight and obesity in adulthood from body mass index values in childhood and adolescence," American Journal of Clinical Nutrition, vol. 76, no. 3, pp. 653-658, 2002.

[8] G. Thorleifsson, G. B. Walters, D. F. Gudbjartsson et al., "Genome-wide association yields new sequence variants at seven loci that associate with measures of obesity," Nature Genetics, vol. 41, no. 1, pp. 18-24, 2009.

[9] R. J. F. Loos and T. Rankinen, "Gene-diet interactions on body weight changes," Journal of the American Dietetic Association, vol. 105, no. 5, pp. S29-S34, 2005.

[10] P. Gordon-Larsen, R. G. McMurray, and B. M. Popkin, "Determinants of adolescent physical activity and inactivity patterns," Pediatrics, vol. 105, no. 6, p. E83, 2000.

[11] I. Labayen, J. R. Ruiz, F. B. Ortega, et al., "Intergenerational cardiovascular disease risk factors involves both maternal and 
paternal body mass index," Diabetes Care, vol. 33, no. 4, pp. 894-900, 2010.

[12] J. J. Reilly, J. Armstrong, A. R. Dorosty et al., "Early life risk factors for obesity in childhood: cohort study," British Medical Journal, vol. 330, no. 7504, pp. 1357-1359, 2005.

[13] C. M. Olson, "Achieving a healthy weight gain during pregnancy," Annual Review of Nutrition, vol. 28, pp. 411-423, 2008.

[14] L. S. Goodell, D. B. Wakefield, and A. M. Ferris, "Rapid weight gain during the first year of life predicts obesity in 2-3 year olds from a low-income, minority population," Journal of Community Health, vol. 34, no. 5, pp. 370-375, 2009.

[15] J. Baird, D. Fisher, P. Lucas, J. Kleijnen, H. Roberts, and C. Law, "Being big or growing fast: systematic review of size and growth in infancy and later obesity," British Medical Journal, vol. 331, no. 7522, pp. 929-931, 2005.

[16] C. Maffels, R. Micciolo, A. Must, M. Zaffanello, and L. Pinelli, "Parental and perinatal factors associated with childhood obesity in north-east Italy," International Journal of Obesity, vol. 18, no. 5, pp. 301-305, 1994.

[17] E. Oken, E. M. Taveras, K. P. Kleinman, J. W. Rich-Edwards, and M. W. Gillman, "Gestational weight gain and child adiposity at age 3 years," American Journal of Obstetrics and Gynecology, vol. 196, no. 4, pp. 322.e1-322.e8, 2007.

[18] P. Moreira, C. Padez, I. Mourão-Carvalhal, and V. Rosado, "Maternal weigh gain during pregnancy and overweight in Portuguese children," International Journal of Obesity, vol. 31, no. 4, pp. 608-614, 2007.

[19] E. Oken, S. Y. Huh, E. M. Taveras, J. W. Rich-Edwards, and M. W. Gillman, "Associations of maternal prenatal smoking with child adiposity and blood pressure," Obesity Research, vol. 13, no. 11, pp. 2021-2028, 2005.

[20] K. Gorog, S. Pattenden, T. Antova, et al., "Maternal smoking during pregnancy and childhood obesity: results from the CESAR Study," Maternal and Child Health Journal, 2009.

[21] T. Harder, R. Bergmann, G. Kallischnigg, and A. Plagemann, "Duration of breastfeeding and risk of overweight: a metaanalysis," American Journal of Epidemiology, vol. 162, no. 5, pp. 397-403, 2005.

[22] M. W. Gillman, S. L. Rifas-Shiman, K. Kleinman, E. Oken, J. W. Rich-Edwards, and E. M. Taveras, "Developmental origins of childhood overweight: potential public health impact," Obesity, vol. 16, no. 7, pp. 1651-1656, 2008.

[23] D. M. Jackson, K. Djafarian, J. Stewart, and J. R. Speakman, "Increased television viewing is associated with elevated body fatness but not with lower total energy expenditure in children," American Journal of Clinical Nutrition, vol. 89, no. 4, pp. 1031-1036, 2009.

[24] B. A. Dennison, T. A. Erb, and P. L. Jenkins, "Television viewing and television in bedroom associated with overweight risk among low-income preschool children," Pediatrics, vol. 109, no. 6, pp. 1028-1035, 2002.

[25] J. C. Lumeng, S. Rahnama, D. Appugliese, N. Kaciroti, and R. H. Bradley, "Television exposure and overweight risk in preschoolers," Archives of Pediatrics and Adolescent Medicine, vol. 160, no. 4, pp. 417-422, 2006.

[26] Z. Tian, T. Ye, X. Zhang et al., "Sleep duration and hyperglycemia among obese and nonobese children aged 3 to 6 years," Archives of Pediatrics and Adolescent Medicine, vol. 164, no. 1, pp. 46-52, 2010.

[27] E. M. Taveras, S. L. Rifas-Shiman, E. Oken, E. P. Gunderson, and M. W. Gillman, "Short sleep duration in infancy and risk of childhood overweight," Archives of Pediatrics and Adolescent Medicine, vol. 162, no. 4, pp. 305-311, 2008.
[28] S. G. Trost, J. R. Sirard, M. Dowda, K. A. Pfeiffer, and R. R. Pate, "Physical activity in overweight and nonoverweight preschool children," International Journal of Obesity, vol. 27, no. 7, pp. 834-839, 2003.

[29] W. B. Strong, R. M. Malina, C. J. R. Blimkie et al., "Evidence based physical activity for school-age youth," Journal of Pediatrics, vol. 146, no. 6, pp. 732-737, 2005.

[30] K. F. Janz, S. M. Levy, T. L. Burns, J. C. Torner, M. C. Willing, and J. J. Warren, "Fatness, physical activity, and television viewing in children during the adiposity rebound period: the Iowa Bone Development Study," Preventive Medicine, vol. 35, no. 6, pp. 563-571, 2002.

[31] K. F. Janz, "Validation of the CSA accelerometer for assessing children's physical activity," Medicine and Science in Sports and Exercise, vol. 26, no. 3, pp. 369-375, 1994.

[32] L. B. Sardinha, F. Baptista, and U. Ekelund, "Objectively measured physical activity and bone strength in 9-year-old boys and girls," Pediatrics, vol. 122, no. 3, pp. e728-e736, 2008.

[33] L. R. Purslow, C. Hill, J. Saxton, K. Corder, and J. Wardle, "Differences in physical activity and sedentary time in relation to weight in 8-9 year old children," International Journal of Behavioral Nutrition and Physical Activity, vol. 5, article no. 67, 2008.

[34] J. J. Reilly, J. Coyle, L. Kelly, G. Burke, S. Grant, and J. Y. Paton, "An objective method for measurement of sedentary behavior in 3- to 4-year olds," Obesity Research, vol. 11, no. 10, pp. 1155$1158,2003$.

[35] R. R. Pate, M. J. Almeida, K. L. McIver, K. A. Pfeiffer, and M. Dowda, "Validation and calibration of an accelerometer in preschool children," Obesity, vol. 14, no. 11, pp. 2000-2006, 2006.

[36] S. Vale, R. Santos, P. Silva, L. Soares-Miranda, and J. Mota, "Preschool children physical activity measurement: importance of epoch length choice," Pediatric Exercise Science, vol. 21, no. 4, pp. 413-420, 2009.

[37] Institute of Medicine NAoS, Ed., Nutrition during Pregnancy, National Academy Press, Washington, DC, USA, 1990.

[38] American Academy of Pediatrics. Committee on Public Education, "American Academy of Pediatrics: children, adolescents, and television," Pediatrics, vol. 107, no. 2, pp. 423-426, 2001.

[39] D.-S. Akram, A. V. Astrup, T. Atinmo et al., "Obesity: preventing and managing the global epidemic," Technical Report Series WHO/NUT/NCD/981, World Health Organization, Geneva, Switzerland, 1998.

[40] A. Rundle, S. Field, Y. Park, L. Freeman, C. C. Weiss, and K. Neckerman, "Personal and neighborhood socioeconomic status and indices of neighborhood walk-ability predict body mass index in New York City," Social Science and Medicine, vol. 67, no. 12, pp. 1951-1958, 2008.

[41] J. Mota and G. Silva, "Adolescent's physical activity: association with socio-economic status and parental participation among a Portuguese sample," Sport, Education and Society, vol. 4, no. 2, pp. 193-199, 1999.

[42] I. Ara, G. Vicente-Rodríguez, L. Moreno, B. Gutin, and J. Casajus, "La obesidad infantil se puede reducir mejor mediante actividad física vigorosa que mediante restricción calórica," Apunts. Medicina de l'Esport, vol. 44, no. 163, pp. 111-118, 2009.

[43] P. Barbeau, M. H. Johnson, C. A. Howe et al., "Ten months of exercise improves general and visceral adiposity, bone, and fitness in black girls," Obesity, vol. 15, no. 8, pp. 2077-2085, 2007. 
[44] B. Gutin, Z. Yin, M. Johnson, and P. Barbeau, "Preliminary findings of the effect of a 3-year after-school physical activity intervention on fitness and body fat: the Medical College of Georgia Fitkid Project," International Journal of Pediatric Obesity, vol. 3, supplement1, pp. 3-9, 2008.

[45] B. Gutin, Z. Yin, M. C. Humphries, and P. Barbeau, "Relations of moderate and vigorous physical activity to fitness and fatness in adolescents," American Journal of Clinical Nutrition, vol. 81, no. 4, pp. 746-750, 2005.

[46] S. Vale, P. Silva, R. Santos, L. Soares-Miranda, and J. Mota, "Compliance with physical activity guidelines in preschool children," Journal of Sports Sciences, vol. 28, no. 6, pp. 603-608, 2010. 


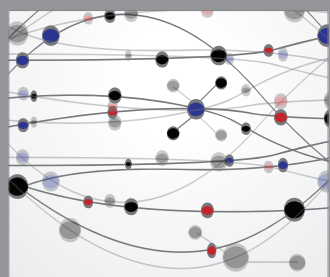

The Scientific World Journal
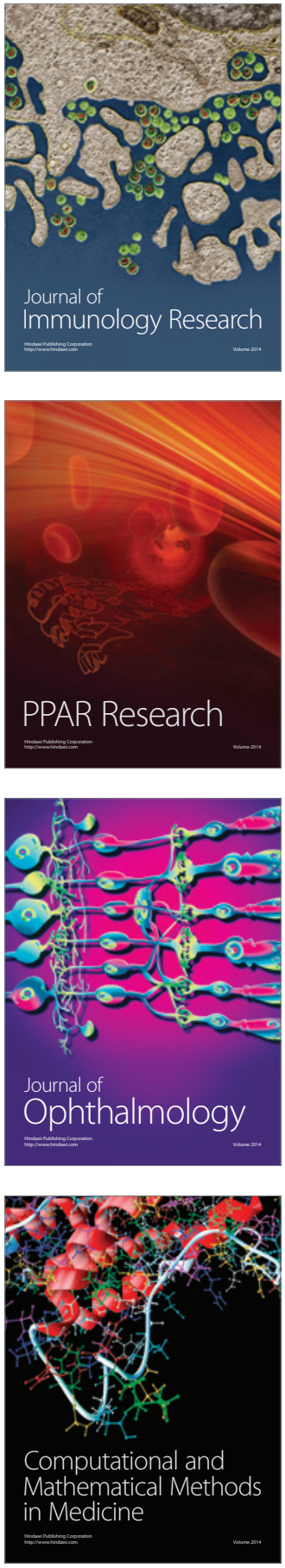

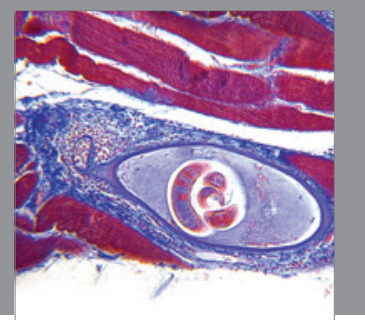

Gastroenterology

Research and Practice
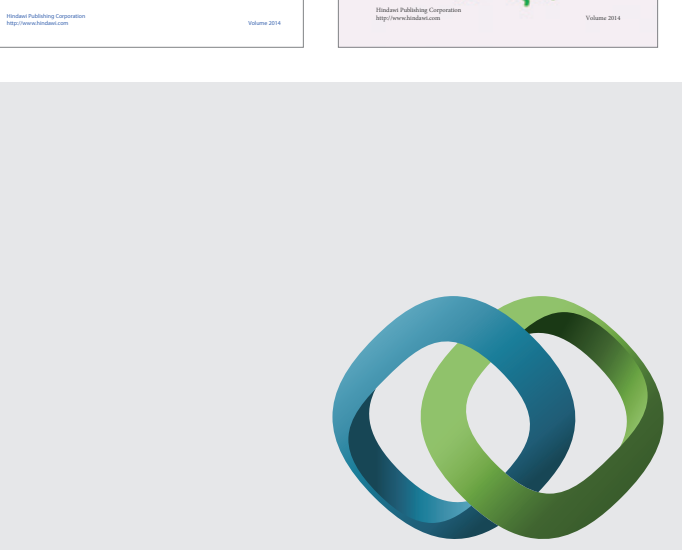

\section{Hindawi}

Submit your manuscripts at

http://www.hindawi.com
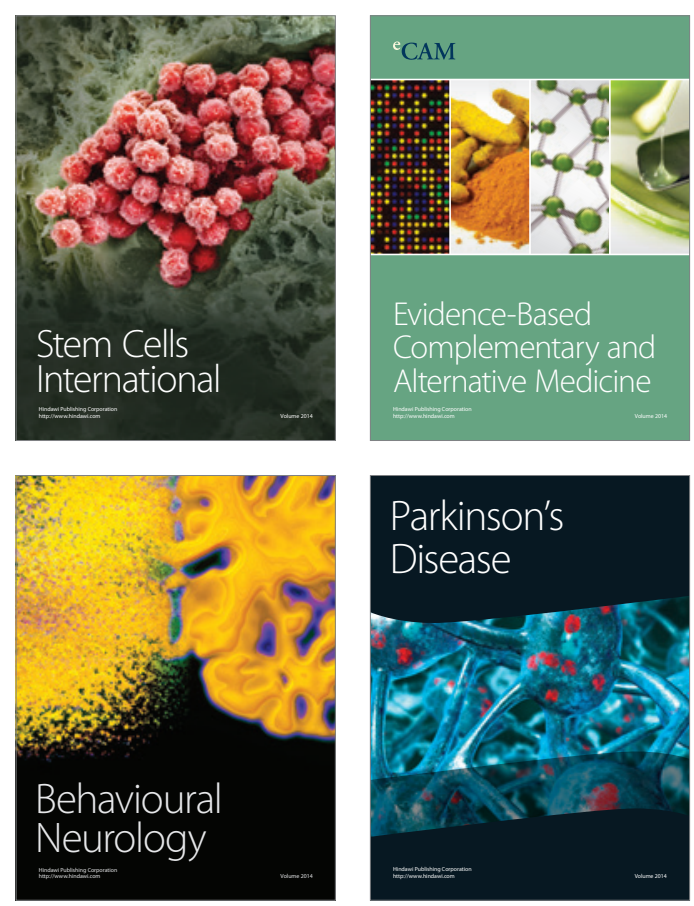

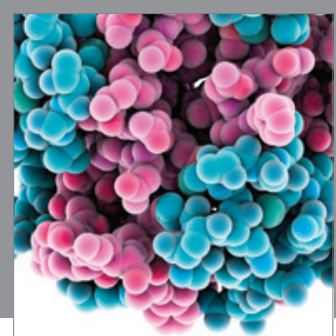

Journal of
Diabetes Research

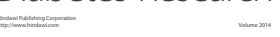

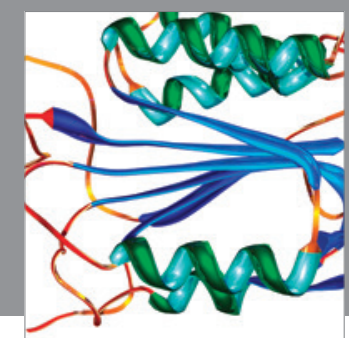

Disease Markers
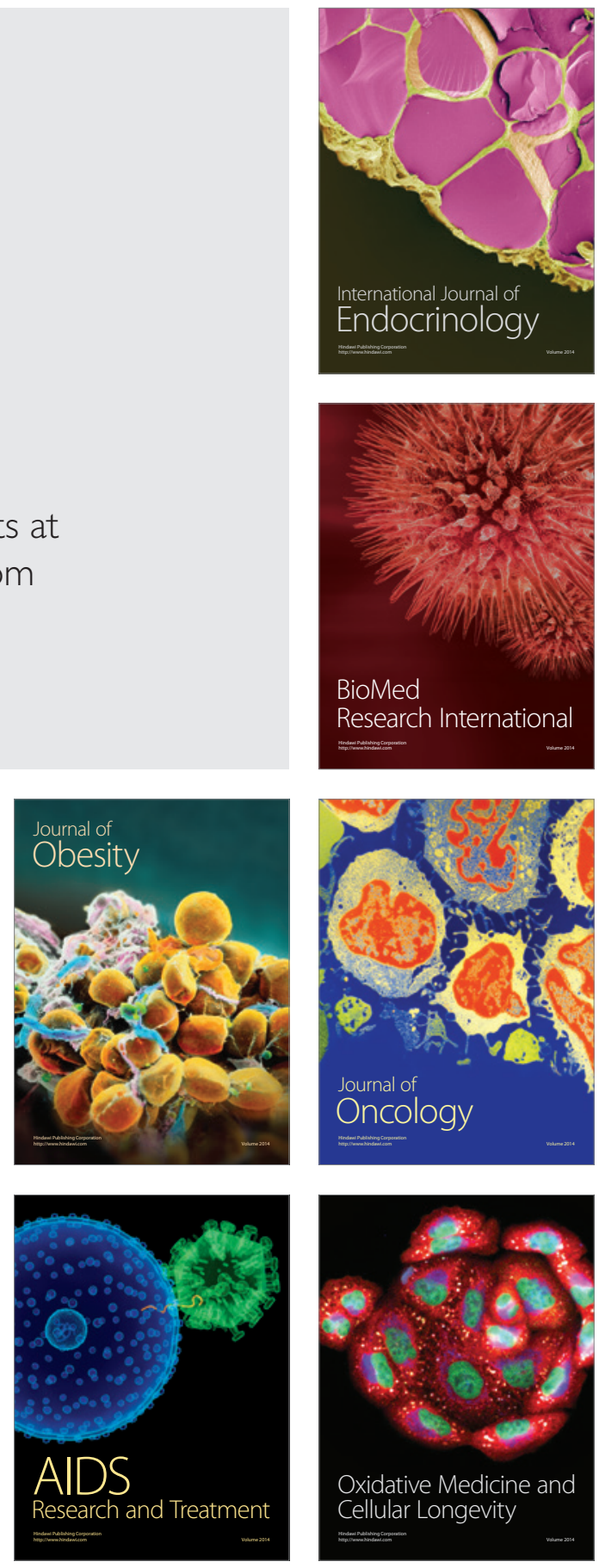